\title{
O desejo juvenil de ser modelo profissional e a mediação da mídia: uma articulação desde o aporte de Martín-Barbero
}

\section{Daniela Maria Schmitz}

Doutora; Universidade Federal do Rio Grande do Sul, Porto Alegre, RS, Brasil danischmitz@ymail.com

\section{Resumo}

Este texto traz parte da problematização de uma tese que investigou as relações entre o consumo midiático de jovens garotas e o desejo de seguir a carreira de modelo. A discussão aqui proposta é acerca da mediação da mídia neste processo de consumo. O conceito é operacionalizado desde o aporte de Martín-Barbero, e os resultados apontam para excelência da mídia como mediação que ajuda a configurar o caráter de "sonho" que este desejo adquire para as jovens entrevistadas.

\section{Palavras-chave}

Mediações. Consumo midiático. Modelos fotográficos. Moda. Juventude.

\section{Introdução}

Este artigo revisita a problemática de uma tese que investigou a construção do desejo juvenil de ser modelo profissional e o papel do consumo midiático em tal processo ${ }^{1}$. Grosso modo, o estudo² filiou-se à abordagem sociocultural do consumo (GARCÍA CANCLINI, 2006) e à teoria dos usos sociais dos meios (MARTÍN-BARBERO, 2003) para investigar como a mídia e a família operam mediações na edificação desse desejo.

Aqui pretende-se discutir a noção de "mediação da mídia", pela perspectiva de Jesús Martín-Barbero, trazendo indícios empíricos de como a lógica midiática interfere no

\footnotetext{
${ }^{1}$ Uma versão preliminar deste texto foi apresentada no Grupo de Trabalho Consumo Comunicação e Subjetividade, do 4oㅡ. Encontro de Grupo de Trabalhos (GTs) - Comunicon, realizado entre 8 e 10 de outubro de 2014 (SCHMITZ, 2014b).

2 Trata-se da tese "Vivendo um projeto em família: consumo midiático, beleza feminina e o sonho juvenil de ser modelo profissional", defendida no Programa de Pós-graduação em Comunicação e Informação da Universidade Federal do Rio Grande do Sul (SCHMITZ, 2013).
} 
consumo de referenciais de beleza feminina, mais especificamente das modelos que atuam no segmento da moda. A proposta é refletir como o desejo de seguir tal profissão pode estar sendo configurado pelo consumo de modelos midiatizadas.

O pressuposto de partida está centrado na importância que o campo midiático adquire na atual configuração social. É a partir do consumo midiático que os sujeitos são informados sobre a maior parte dos acontecimentos e o curso do mundo, o que atribui à mídia um papel fundamental em várias experiências comunicativas e também nas lógicas de interação social. Tal discussão sobre a centralidade midiática - ou a importância que adquire a mediação da tecnicidade - acompanha a reflexão contemporânea de MartínBarbero (2016, 2014, 2009a, 2009b). Contudo, é preciso ponderar que, em sua visão, a técnica é muito mais do que viabilizam os meios, e a comunicação é muito mais do que os próprios meios, é "interação que possibilita a interface de todos os sentidos" (MARTíNBARBERO, 2009b, p. 153).

Assim, o que entra em pauta aqui é o consumo midiático de modelos femininas, mas também a forma como as famílias vivem e constroem o sonho de adentrar o universo da mídia a partir do desejo de ser modelo da filha, e, muitas vezes, também dos pais. Em última instância, o processo investigado é conformado e atravessado pelas mediações da mídia e da família, definidas como importantes em função de indícios empíricos construídos em uma longa pesquisa exploratória com garotas que aspiravam à carreira de modelo.

Deste modo, ainda que o artigo esteja centrado na discussão sobre a mediação da mídia, a familiar também estará implicada, já que o intuito foi compreender como a lógica midiática perpassa a estrutura e as relações familiares, sem, no entanto, substituir ou suplantar laços outros que formam vínculos.

\section{A mediação da mídia}

Na obra-clássica De los medios a las mediaciones, publicada originalmente em 1987, o espanhol-colombiano Jesús Martín-Barbero propõe um novo olhar sobre a comunicação desde a cultura. Argumenta sobre a necessidade de se questionar e analisar problemáticas comunicacionais desde um outro lugar, não circunscrito à produção ou ao consumo, mas partindo dos espaços em que estes âmbitos se encontram e se enfrentam: as mediações sociais.

Neste conceito, Martín-Barbero (2003) considera uma interação entre estruturas e dinâmicas sócio-culturais para emersão dos sentidos fabricados via consumo e recepção de 
produtos midiáticos ${ }^{3}$. As muitas instâncias que interagem nesse processo criam um variado sistema de trocas que se afasta de uma ideia de verticalidade na comunicação, na qual o receptor seria dependente ou manipulável. Deve-se muito a esta noção para pensar a produção de sentidos deslocada da centralidade dos meios, posição que, por muito tempo, foi por eles ocupada, vistos de forma hegemônica como administradores das operações de sentido.

No período em que a obra supracitada foi lançada, imperava o mediacentrismo nas análises do campo comunicacional, no cenário Latino Americano. A discussão sobre o poder da comunicação estava concentrada nas possibilidades das novas tecnologias e o que Martín-Barbero propõe, naquele momento, é uma ideia ampliada que não descura dos meios, mas desloca o olhar sobre sua agência. Em suas palavras: "Centrei minha exposição na não contemporaneidade entre as tecnologias de comunicação e seus modos de uso na América Latina. Incluída a assimetria entre a sintaxe dos discursos midiáticos e a gramática das mediações desde a qual a gente os lê, os ouve e os vê." (MARTíN-BARBERO, 2004, p. 23, grifos do autor).

Portanto, a proposta de compreender o processo comunicacional desde as mediações transcende a ideia de análise centrada ou nos meios, ou na recepção, uma vez que a proposta visa justamente a superar a dicotomia entre produção e consumo. Para tanto, o autor trabalhou em várias versões do que chamou de "mapa noturno"4, uma proposta investigativa peculiar que avança e se remodela na tentativa de configurar as conexões que entretecem comunicação e cultura.

A ideia aqui não é retomar a trajetória dos mapas, o que recentemente foi empreendido por Sifuentes e Escosteguy (2016). E também porque o "mapa barberiano" não foi de fato operacionalizado na pesquisa, visto que o recorte se deu em razão de duas mediações fundamentais à problemática da tese. Assim, o que se propõe é, em um primeiro momento, situar o leitor em relação ao conceito de mediações e adentrar especificamente na discussão sobre a mediação da mídia, ou da tecnicidade, como Martín-Barbero prefere empregar. Esta mediação está intimamente relacionada às novas tecnologias, que são frequentemente tematizadas ao longo da obra do autor e recebem maior atenção à medida que adquirem densidade cultural, social e técnica ao se entrelaçarem com a vida social.

\footnotetext{
${ }^{3}$ Em Schmitz (2015a), discutem-se as distinções entre as perspectivas da recepção e do consumo midiático.

${ }^{4}$ Em Martín-Barbero (2016), há uma explicação para o termo empregado: diz ele que se apropriou da ideia de mapa da obra "Voo noturno", de Antoine de Saint-Exupéry, cujo personagem principal revive experiências do autor quando trabalhou para o Correio Aéreo francês em incertas e misteriosas viagens noturnas.
} 
Pensando com Martín-Barbero, entende-se que as mediações podem ser tomadas como determinados "lugares" a partir dos quais se constituem os processos de apropriação e usos dos produtos comunicativos. Partir das mediações para se operar a análise significa partir "[...] dos lugares dos quais provêm as construções que delimitam e configuram a materialidade social e a expressividade cultural [dos meios]." (MARTÍN-BARBERO, 2003, p. 304).

Assim, entende-se que as mediações são lugares nos quais processos simbólicos e de representação se operam na produção dos sentidos; são instâncias nas quais os sentidos construídos desde o midiático se moldam e processam, conectando elementos tanto da lógica produtiva como das práticas dos sujeitos. Nesse processo, a metáfora empregada por Escosteguy (2010, p. 107), em que as mediações “[...] são pontes que permitem alcançar um segundo estágio, sem sair totalmente do primeiro." Ajuda a pensar essa imbricação que ocorre nas instâncias de mediação.

Na pesquisa a qual este texto se reporta, para tratar da mediação da mídia, partiu-se da premissa de que a mídia tem participação quase que fundamental nos processos de comunicação contemporâneos. Como propõe Martín-Barbero: "O meio não se limita a veicular ou traduzir as representações existentes, tampouco pode substituí-las, mas começou a constituir uma cena fundamental da vida pública." (MARTÍN-BARBERO, 2003, p. 14 , grifos do autor).

Sua visão sobre a importância dos meios vai se adensando à medida que seus novos "mapas noturnos", especialmente ao final da primeira década dos 2000, aproximam as mediações da tecnicidade e da identidade. Como indica o próprio (MARTÍN-BARBERO, 2009a), estas duas mediações entram no mapa substituindo outras mais "tradicionais" - no caso, institucionalidade e socialidade - uma inclusão que, a seu ver, abre espaço à "transformação", ou seja, à mutação cultural que, em grande medida, é tributária de questões relativas à técnica. No movimento também é possível depreender o quanto os processos de construção identitária são afetados por novos dispositivos e processualidades.

Como dito anteriormente (SCHMITZ, 2014a), entende-se que a participação da mídia ocorre em vários níveis da vida social e nas necessidades cada vez maiores de entendimento e apropriação das lógicas midiáticas de atuação para experienciar o mundo. Na argumentação de Gomes (2017), pesquisar sobre a mídia, em seus processos estruturantes e modos de produção, é operar com elementos essenciais para interpretar os interrelacionamentos sociais e humanos de nosso tempo. 
Lipovetsky (1989), pensador chave para tratar de questões relativas à moda, aborda a questão do midiático com vistas em sua incidência sobre os sujeitos e pondera que:

[...] a mídia não asfixia o sentido da comunicação, não põe fim à sociabilidade, mas reproduz de uma outra maneira ocorrências de troca social. Instituem-na essencialmente sob uma forma menos ritualizada e mais livre. [...] [os indivíduos] comunicam-se de maneira mais estilhaçada, mais informal, mais descontínua, de acordo com os gostos de autonomia e de rapidez dos sujeitos. (LIPOVETSKY, 1989, p. 235).

Cabe, a esta altura do texto, esclarecer que Lipovetsky (1989) percebe uma grande aproximação entre moda e mídia, em suas lógicas de atuação. Assim como entende que o "modelo" de renovação da moda foi adotado por diversos segmentos, entre eles o próprio campo midiático. Destaca-se, então, que, para o autor, a dinâmica da moda é uma "forma" geral em ação no todo social, e a obsolescência programada, tão em prática no mercado atual, já regia a moda desde seu surgimento, em meados do século XIV, ainda que em marcha lenta, se comparada aos atuais padrões de velocidade de renovação.

A relevância de estudar as relações entre esses dois campos sociais está centrada no próprio objeto de pesquisa: a profissão de modelo está intimamente ligada à moda e tem sua legitimação na medida em que é midiatizada. E, ao observar a convergência e o diálogo entre moda e mídia, Lipovetsky (1989) enumera que:

a) o "tempo-moda" (acelerado) também está presente nos meios de comunicação;

b) ambas estão interessadas no sucesso e lucro imediato;

c) há especial dedicação a construção e difusão de imagens;

d) ambas trabalham com a construção de celebridades;

e) oferecem uma diversidade de ofertas para todos os gostos;

f) são presenteístas, uma vez que suas existências não investem em prolongamentos.

Não cabe aqui discutir quem assume o papel de protagonista na instituição e difusão destas lógicas, o que já foi empreendido em Schmitz (2015b), mas pontuar que moda e mídia atuam com racionalidades muito próximas.

Fechado o parênteses que ajudou a demarcar uma forte relação entre moda e mídia que aqui se considera desde Lipovetsky (1989), volta-se à discussão da noção de mediações. Ronsini (2012), ao tratar da mediação da tecnicidade desde Martín-Barbero, também elenca aspectos da aproximação entre a vida cotidiana e a lógica midiática, por exemplo: 
Os meios de comunicação como aparatos tecnoperceptivos, especialmente os meios audiovisuais, mobilizam-nos para a simultaneidade das tarefas, abolem o passado e o futuro na fabricação do império das novidades que necessitam ser consumidas com voracidade, instantaneamente, e resultam em uma vivência fragmentada e heterogênea tal como o ritmo das imagens nas telas da televisão e do computador. (RONSINI, 2012, p. 69).

Em um estudo que envolve o padrão de beleza feminina midiatizada consumido por jovens que desejam figurar neste espaço de referenciais de aparência é possível depreender uma incidência considerável dos meios de comunicação no processo. Essa atuação da mediação da mídia está calcada, entre outras questões, no conhecimento de lógicas midiáticas relativas à beleza feminina por parte das garotas e também de seu núcleo familiar. Assim, é preciso que elas (re)conheçam o padrão estético vigente, com valorização da juventude, magreza, altura diferenciada e, de preferência, características europeias (olhos e cabelos claros) para aumentar as chances de sucesso na profissão.

A família deve compartilhar do mesmo conhecimento e também tem sua produção de sentidos sobre a carreira marcada pela mesma mediação. Isso porque os padrões de aparência feminina são amplamente difundidos e, em grande parte, construídos via mídia e a lógica midiática possivelmente marque o cotidiano familiar.

Deste modo, é possível tomar a mediação da tecnicidade, nas palavras de MartínBarbero, como estratégica, pois "A tecnicidade é menos assunto de aparatos do que de operadores perceptivos e destrezas discursivas." (MARTÍN-BARBERO, 2003, p. 18, grifo do autor). Assim, ela passa a operar como um "organizador perceptivo" (MARTÍN-BARBERO, 2004, p. 235), conforme propõe em outro texto em que discute o pioneirismo de Walter Benjamin no estudo da relação das inovações da tecnicidade com as transformações do sensorium, dos modos de percepção e experiência social.

Alguns autores assumem a noção de midiatização para se referir especificamente aos processos de ação do midiático sobre os campos e a vida social dos sujeitos, embora estejam longe de um consenso ou mesmo de uma conceituação mais definitiva para o fenômeno. A discussão aponta para sua emergência em meados do século passado, e o centro a partir do qual o discutem é a participação de processos midiáticos na dinâmica social. Esta discussão se dá por dois ângulos: um centrado nas relações entre os campos sociais (RODRIGUES, 2000) e, outro, nas instâncias de produção de sentido, nas quais a mídia figuraria como uma matriz configuradora de sentidos (MATA, 1999). 
Verón (1997) debruça-se sobre o processo de midiatização a partir da centralidade da mídia nas trocas sociais, da participação dos meios de comunicação em mecanismos de funcionamento social e das novas sociabilidades que surgem a partir de novas possibilidades técnicas. $\mathrm{O}$ autor aponta para uma conceituação de comunicação midiática na qual se articulam os dispositivos tecnológicos, as condições específicas de produção e as práticas de recepção, numa imbricação entre a mídia, as instituições e os atores individuais.

Para Braga, pensar a midiatização também é considerar a perspectiva de processo: "[...] midiatização como processo comunicacional da sociedade, mais do que como 'ação das mídias' sobre a sociedade." (BRAGA, 2011, p. 68). E, para o autor, a centralidade midiática vai além da assumpção de lógicas que lhe são próprias (entre elas as práticas que são regidas por instâncias econômicas, políticas, institucionais, informativas, profissionais, interacionais), pois entende a midiatização como “[...] algo muito mais diversificado, menos globalmente apreensível, mais plural - e certamente menos conhecido - do que lógicas da mídia." (BRAGA, 2015, p. 26).

Ainda que os lugares a partir dos quais se discuta os conceitos de mediação e midiatização sejam distintos, vê-se que há maior convergência do que discrepância nas duas noções, principalmente ao se tomar as revisitas ao conceito de mediação efetuadas por Martín-Barbero (2004, 2009a, 2009b) e a discussão de midiatização proposta por Braga (2011). Para este último, a enunciação do termo mídia/midiático não se refere exclusivamente à mídia-empresa ou à mídia-tecnologia ou, como já citado, não se trata de observar apenas como as lógicas da mídia são apropriadas em outros campos. Braga indica que a reflexão deva partir dos processos comunicacionais envolvidos no fenômeno ou, ainda, a “[...] um conjunto complexo de ações de sociedade [...]” (BRAGA, 2011, p. 69).

Desta forma, nas referências aos processos de midiatização da sociedade, a partir dos autores supracitados, há proximidades com a discussão acerca da mediação da tecnicidade de Martín-Barbero. Contudo, a opção teórica na tese recaiu sobre a noção de mediação, que foi eleita como entrada de análise no objeto pela trajetória e importância do conceito, tomado como basilar em grande parte dos estudos de recepção e consumo cultural na América Latina.

Assim, na problematização teórica-metodológica da pesquisa realizada, os processos de midiatização e a mediação da mídia são considerados como instâncias impregnadas na organização social que participam da configuração de sentidos, marcando, modelando e estruturando a interação e a percepção das jovens no consumo dos conteúdos midiáticos 
que ostentam e divulgam as modelos. Ao apropriarem-se das lógicas midiáticas de operação - aceleração, renovação, instituição de padrões de beleza feminina, centralidade na imagem, como propõe Lipovetsky (1989) - para construir o seu projeto de vida de adentrar o universo midiático estão incorporando e se apropriando do discurso e protocolos da mídia em seu cotidiano. Dito de outro modo, existe uma construção e uma ação (no caso das garotas que já buscam a carreira de modelo) a partir do que compreendem ser uma exigência da mídia.

Além disso, pensando nas imbricações entre as lógicas midiáticas e os usos operados pelas adolescentes dos padrões de beleza midiatizados pode-se propor que a mídia é o lugar em que a profissão de modelo se efetiva. Seja nos editoriais de moda das revistas, nas capas das mesmas, ou nas peças publicitárias que ostentam modelos e que perfazem praticamente o circuito de todos os meios. É nos meios de comunicação que o glamour, o sucesso e o sonho que envolve a profissão se processam e se concretizam, sendo depositários do desejo enunciado pelas garotas com base no imaginário e nas representações construídas para a profissão.

Deste modo, uma pressuposição que acompanhou o estudo desde o princípio era o papel central encarnado pela mídia. Considerou-se, assim, que o discurso midiático sobre a beleza feminina operava como um organizador perceptivo capaz de orientar e propulsar as práticas em busca desse padrão de aparência.

\section{A mediação da mídia no consumo midiático das modelos}

Antes de adentrar a discussão sobre a mediação da mídia no objeto/fenômeno investigado, expõe-se de forma breve a metodologia empregada no estudo. 0 trabalho de campo $^{5}$ contou com uma combinação de métodos e procedimentos pensados como estratégia multimetodológica (LOPES et al., 2002). De forma resumida, na pesquisa foram empregadas as seguintes técnicas: entrevistas individuais e em dupla (mãe e filha), questionários aplicados online e presencialmente, entrevistas com profissionais de agência de modelos e observação participante de seleções de modelo. No total, foram entrevistadas 120 garotas e, na construção dos dados, cada técnica foi aplicada com grupos distintos de jovens. Como principal justificativa para este procedimento metodológico, destaca-se que o

${ }^{5} 0$ trabalho de campo foi realizado em 2012 e 2013. 
cerne da investigação dava conta do contexto do "sonho coletivo" de ser modelo e não de histórias particulares em relação a esse desejo.

$\mathrm{Na}$ análise dos dados, pode-se verificar que, para o grupo pesquisado, a mídia em algum momento da vida assume o papel de mediação entre o cotidiano e o sonho de ser modelo, tanto em perspectiva sincrônica como diacrônica. Nesta última, a mídia aparece especialmente na instauração do desejo de ser modelo: 32,7\% apontaram o consumo midiático como fundamental para o despertar do sonho. Para uma maioria $(96,8 \%)$, a mídia é a principal fonte atual de informação sobre esse universo, oferecendo dicas, informações, estímulos, ensinamentos e referências para inspiração, admiração e imitação. São a internet, a TV por assinatura e as revistas que aparecem como proeminentes, sendo que tal resultado pode ser associado ao fato de que esses meios ofertam maior quantidade de conteúdos sobre o universo da profissão.

A mídia também é vista como sinônimo de projeção para algumas jovens, como se pode ver no depoimento de uma garota de 19 anos. Ela declara nunca ter pensado em participar de algum concurso de beleza ou de modelo, até se iniciar na profissão (SCHMITZ, 2013, p. 263):

Hoje eu já penso porque hoje eu preciso de oportunidade, sabe? De alguma forma a gente tem que aparecer, a gente tem que mostrar a cara e nesses concursos tu mostra pra todo mundo, sabe? Tu vê na TV, tu vê na internet. Então hoje eu penso bem mais em participar desses concursos ${ }^{6}$.

O que subjaz tal fala é a noção de que a mídia é, senão criadora por completo, impulsionadora de sucesso, o que está de acordo com a argumentação de Lipovetsky (1989) que, tanto a mídia, como a moda, estariam interessadas no sucesso e lucro imediato, assim como na construção de celebridades. Outra aproximação proposta pelo autor é a importância que os dois campos dedicam à imagem e o que os concursos de beleza fazem é justamente colocar ênfase nesse âmbito.

Dessa forma, é possível vislumbrar que as garotas percebem algumas lógicas a partir das quais a mídia atua e, ao seu modo, tentam adentrá-las, seja pela participação em concursos de beleza que seriam midiatizados e ampliariam as possibilidades de reconhecimento ou simplesmente conhecendo pessoas "da mídia" que poderiam facilitar o

${ }^{6}$ Este e outros excertos de falas das informantes foram coletados no trabalho de campo da tese a qual este artigo se reporta (SCHMITZ, 2013). 
seu acesso a este mundo. Este é o caso de outra garota, de 18 anos, que revela que a curta atuação como modelo já lhe possibilitou essa oportunidade (SCHMITZ, 2013, p. 263):

Porque nesse meio tu acaba conhecendo muitas pessoas interessantes. Eu, por exemplo, já conheci pessoas de dentro do SBT, fotógrafos importantes dentro do cenário brasileiro... Isso é uma coisa que é muito boa. É muito boa porque são contatos que tu acaba criando e tal.

Assim, a mídia se constitui de um espaço privilegiado, de autoridade, de projeção e de legitimação, pois como já se pontuou, o "estar na mídia” é sinônimo de sucesso.

A forma de tratamento da profissão nos meios elenca o sonho de ser modelo como um conto de fadas midiático pós-moderno, muito próximo da história de Cinderela, no qual basta que a menina seja descoberta por uma fada madrinha (agência, fotógrafo, vencer um concurso, ganhar um reality show) para sair do estado de gata borralheira para o de princesa (modelo de aparência). Essa lógica do "foi descoberta" está presente nas trajetórias midiatizadas de algumas modelos. Contudo, o conto de fadas midiático da profissão de modelo não conduz as garotas aos braços de um príncipe encantado, mas as deixaria abraçadas à fama que a mídia lhes oferta.

Cabe citar também que, embora não se tenha realizado uma análise dos conteúdos midiáticos mais consumidos pelas garotas, uma breve observação permitiu perceber, além da ideia recorrente de que as modelos "são descobertas", uma estrutura discursiva centrada nas ideias de sucesso, glamour, projeção e "facilidade" que estariam inscritas nessa profissão. Quanto aos aspectos de glamour, chama atenção o fato de uma grande parte das garotas ter citado o consumo do programa midiático mais espetacularizado do atual contexto de desfiles: o Victoria's Secrets Fashion Show ${ }^{7}$. E seu consumo se dá via TV a cabo, no canal TNT; na televisão aberta, no SBT; e em vídeos buscados na internet. Uma garota de 16 anos declara: “[...] o meu o meu grande sonho assim pra trabalhar mesmo, é na Victoria's Secrets. Nossa! Mas até lá... Mas, com certeza, meu Deus, é, esse é um grande objetivo." (SCHMITZ, 2013, p. 265).

Entende-se que essas representações da profissão, a repetição com que são expostas e a amplitude de massa que adquirem ao serem midiatizadas podem ajudar a moldar os sentidos produzidos no consumo midiático. E é preciso considerar também a envergadura desse processo, pois, com base no que propõe Martín-Barbero (2009a), o caráter transversal

\footnotetext{
7 Trata-se de um desfile anual de uma marca de lingerie americana que recebe bastante destaque nos meios de comunicação. No universo das modelos, participar deste evento é sinônimo de sucesso na carreira.
} 
com que os meios, especialmente os digitais, permeiam o cotidiano resulta em uma verdadeira revolução. Inclusive, o autor questiona as formas possíveis de se assumir tamanha complexidade social e perceptiva incorporada pelos meios sem cair na fascinação tecnológica. Ainda assim, em sua visão, a tecnicidade é uma mediação estratégica, pois “[...] é menos assunto de aparatos do que de operadores perceptivos e destrezas discursivas [...]" (MARTÍN-BARBERO, 2003, p. 18, grifos do autor).

Por tudo que se tratou até aqui, compreende-se que a mídia constitui, além da principal fonte de informação e acesso à profissão de modelo (seja pela inscrição via internet em concursos ou pela submissão de material fotográfico para avaliação das agências), de uma importante mediação tanto no consumo midiático sobre a carreira, na produção de sentidos e também no sonho de ser modelo, já que atua como "organizador perceptivo", tal qual argumenta Martín-Barbero (2004, p. 235). Essa percepção barberiana também está próxima do que Mata (1999) propõe quando anuncia a mídia como uma matriz configuradora de sentidos.

Seguindo essa linha de pensamento, pode-se arriscar que, no caso do consumo midiático de informações sobre a profissão e do sonho de ser modelo, a mediação da mídia adquire o caráter de entorno, tal qual propôs Martín-Barbero (2009a), ao se apropriar da argumentação de Javier Echeveria. E infere-se que esse entorno seria circular, pois, em alguns casos, o sonho nasce a partir do consumo midiático e se alimenta desse consumo para reforçá-lo e mantê-lo. E essa circularidade só seria quebrada na realização do sonho, ou seja, no adentramento ou penetração no âmbito midiático a partir da atividade de modelo. Essa interpretação toma por base o fato de que a maior parte das meninas que já experienciou o cotidiano da profissão relata que a mídia não é fiel à realidade da profissão.

Portanto, a experiência concreta dentro da atividade de modelo demarca em grande medida os sentidos produzidos para as ofertas midiáticas. Pode-se citar, inclusive, com base em alguns depoimentos, que quanto mais negativa for a experiência de ser modelo, mais espaço a mídia perde como mediação na produção de sentidos.

Com base no que se expos até aqui, reitera-se que esse organizador perceptivo citado por Martín-Barbero (2004) ou essa matriz configuradora de sentidos que a mídia incorporaria, segundo Mata (1999), é modulada pelas experiências das garotas dentro da profissão. Em última instância, a mídia não substitui a vivência no que diz respeito à experiência concreta da profissão. Em alguns casos, inclusive, a mediação da competência cultural, construída na experiência da profissão se sobrepõe à mediação da mídia. Tal 
percepção reforça a visão ponderada de Martín-Barbero em relação aos meios, especialmente a técnica, pois os vê atravessando transversalmente o processo de comunicação na sociedade: eles são centrais ao condensar e intersectar redes de poder e de produção cultural, mas não encarnam o papel de principal mediador entre as pessoas e o mundo.

Se por um lado essa constatação reduz a participação do midiático como mediação na construção de sentidos sobre a profissão para as que já atuaram como modelos, ela aumenta consideravelmente o papel da mídia na construção e principalmente na manutenção do desejo de ser modelo entre aquelas que ainda estão tentando. Isso porque se pressupõe que esses conteúdos sejam grandes referências para alimentar as imagens mentais que as garotas constroem sobre este sonho. Esse entendimento é amparado na argumentação de Campbell (2001), para quem a experiência de fantasiar é sempre muito mais prazerosa e perfeita que o real. E, pelo conjunto total de dados construídos em campo, é possível inferir que a prática da fantasia, distinta do devaneio que sofre restrições para adaptar-se à realidade, como defende Campbell (2001), seja a mais operada pelas garotas.

Essa última inferência está bastante centrada na apropriação que as jovens realizam do padrão de beleza midiática das modelos, pois elas fisicamente estão bem distantes do padrão vigente. Embora o consumo midiático sobre modelos exista e seja bem proeminente em muitos casos, uma restrita minoria (cinco garotas em 75 abordadas pessoalmente) está dentro do padrão atual das modelos profissionais e em torno de três teriam algum potencial, pelos traços do rosto e pela altura, desde que perdessem peso para corresponder às exigências do mercado. Essa é uma avaliação particular que parece estar de acordo com a relação desigual entre o número de candidatas e garotas que efetivamente se iniciam e se mantém na profissão, segundo informações das próprias agências de modelos.

Essa consideração sobre a inadequação física das garotas, e aqui não se trata da distância de apenas alguns quilos, é uma das surpresas da pesquisa, pois se pressupunha que as exigências do padrão de beleza feminina das modelos incidiriam de uma forma mais acentuada sobre um grupo de garotas que desejasse seguir essa profissão. No entanto, não foi isso que se encontrou em campo. Algumas jovens reconhecem as exigências de magreza, altura e beleza que a profissão requer, mas, mesmo não estando dentro dele, não deixam de sonhar e algumas, inclusive, de tentar espaço na profissão.

A rigidez de cuidados estéticos não parece fazer parte do dia a dia de quem está apenas sonhando com a carreira, segundo os dados coletados, embora elas demonstrem 
interesse por conteúdos midiáticos ligados à moda e à beleza. Infere-se que essa atenção à estética pode estar relacionada à presença social feminina imbuída de maiores exigências quanto à aparência, como propõe Berger (1999). E o tipo de consumo midiático que se destacou neste quesito foi o da programação da TV por assinatura, em que programas de moda são assistidos por $46,5 \%$ e de beleza por $20,9 \%$.

0 que se está tentando demonstrar aqui é que a mediação da mídia parece ser bastante relevante na alimentação do sonho, provendo insumos para que as garotas fantasiem com a carreira, mesmo que não haja possibilidades reais de concretização em função do padrão de beleza vigente. E o que foi percebido ao longo de toda investigação é que a mídia parece ser uma especialista na oferta de conteúdos que associem a carreira de modelo ao glamour, à facilidade, à fama e ao dinheiro, o que pode estimular esse desejo e servir de insumo para fantasias.

\section{Considerações finais}

Para finalizar, a pressuposição de que a mídia seria uma mediação por excelência na construção do desejo de ser modelo foi efetivamente confirmada, ao menos para o grupo investigado. Porém, o que se aventava era a maior participação midiática na difusão de referenciais de beleza em vigor na profissão, culminando num regramento das práticas das garotas em busca desse padrão e aparência. Mas o que a mídia parece desempenhar melhor é o seu papel na criação e projeção das representações de fama da carreira de modelo, tanto que o padrão de beleza feminina midiática parece estar em segundo plano, ao menos no consumo e na produção de sentidos das jovens desta pesquisa. Enfim, o sonho de ser modelo parece ser maior do que toda a regulação que a mídia, conjuntamente com a moda e o mercado de modelos, pode operar sobre a aparência feminina, que parece sofrer mais sanções quando a exigência parte da própria agência de modelos, no contraponto entre fantasia e realidade já apontado.

Assim, a mídia parece ser mais uma matriz modeladora de sonhos, no caso das entrevistadas, valendo-se da discussão de Mata (1999), para quem a mídia seria uma matriz configuradora de sentidos. Essa conclusão quanto à participação do midiático está de acordo com o que postula Campbell (2001), para quem o sujeito moderno é um artista do sonho e pelo que tudo indica, essas garotas são exemplares avançados nessa arte, ao menos no que tange à profissão de modelo. 0 autor defende que essa aptidão imaginativa cria fantasias tão convincentes que os indivíduos reagem subjetivamente a elas com se fossem reais. E os 
dados construídos demonstraram que elas realmente acreditam que podem ter sucesso em uma carreira de modelo, mesmo que estejam muito distantes do padrão de beleza vigente na profissão.

A discussão da referida tese não foi pautada por questões relacionadas à identidade feminina, embora se reconheça que o corpo é uma dimensão importante na presença social das mulheres (BERGER, 1999; LIPOVETSKY, 2000; DEL PRIORE, 2000), inclusive em perspectiva histórica. Cabe pautar, então, concordando com García Canclini (2005), que as identidades contemporâneas se configuram em grande medida por meio do consumo, no caso referido, o consumo midiático de conteúdos sobre modelos. 0 que reforça também a importância das mediações da tecnicidade e da identidade no panorama sociocultural, como já foi postulado por Martín-Barbero (2009a). Campbell (2009) também manifesta concordância com a relação consumo-identidade, sendo que essa construção identitária está mais inscrita nas reações aos produtos e não nos produtos em si. Lembrando que a chave do entendimento para o fenômeno do consumo, para o autor, está no processo de querer e desejar, e aqui, além de querer e consumir conteúdos midiáticos sobre modelos, as garotas desejam ser este "modelo de aparência", o que demarca um duplo desejo no consumo midiático, mesmo que circunscrito a um campo abstrato.

Não se pode afirmar que essa ênfase nos sentidos de sonho retire da mídia o poder de ajudar a moldar a figura feminina, já que também existe a identificação do padrão de modelo como sendo magra e alta, embora com distintas apropriações operadas pelas garotas. Portanto, mesmo que o principal uso/sentido operado desde o consumo midiático das modelos seja o do prazer auto-ilusivo operado pela fantasia de pertencer a esse universo, dentro da proposta de Campbell (2001), considera-se que esse processo ocorra dentro de um contexto de exigência de beleza a que as mulheres estariam expostas, uma padronização discursiva da mídia acerca da carreira de modelo e também da aparência feminina. Enfim, ser bela ainda é uma responsabilidade da própria mulher (WOLF, 1992; DEL PRIORE, 2000; NOVAES, 2006), embora pareça que as modelos sejam agraciadas com o dom da beleza e que só precisam é contar com uma boa fada madrinha que as descubra e lhes abra as portas da mídia. A mesma mídia que hoje ocupa o papel de prescritora da forma como a mulher deve parecer, como pontuou Del Priore (2000), preenchendo um espaço que, em outros tempos, fora ocupado pelo padre, marido ou médico. 


\section{Referências}

BERGER, John. Modos de ver. Rio de Janeiro: Rocco, 1999.

BRAGA, José Luiz. Lógicas da mídia, lógicas da midiatização? In: FAUSTO NETO, Antônio et al. Relatos de investigaciones sobre mediatizaciones. Rosario: UNR, 2015.

BRAGA, José Luiz. Constituição do campo da comunicação. Verso e Reverso, São Leopoldo, v. 25, n. 58, jan./abr., 2011.

CAMPBELL, Colin. Eu compro, logo sei que existo: as bases metafísicas do consumo moderno. In: BARBOSA, Lívia; CAMPBELL, Colin. Cultura, consumo e identidade. Rio de Janeiro: FGV, 2009. p. 47-64.

CAMPBELL, Colin. A ética romântica e o espírito do consumismo moderno. Rio de Janeiro: Rocco, 2001.

DEL PRIORE, Mary. Corpo a corpo com a mulher: pequena história das transformações do corpo feminino no Brasil. São Paulo: Editora Senac, 2000.

ESCOSTEGUY, Ana Carolina. Cartografias dos estudos culturais: uma versão latinoamericana. Belo Horizonte: Autêntica, 2010.

GARCÍA CANCLINI, Néstor. El Consumo Cultural: uma propuesta teórica. In: SUNKEL, Guilhermo. El consumo cultural en América Latina: construcción teórica y líneas de investigación. 2. ed. Bogotá: Convenio Andrés Belo, 2006. p. 72-95.

GARCÍA CANCLINI, Néstor. Consumidores e cidadãos. Rio de Janeiro: UFRJ, 2005.

GOMES, Pedro Gilberto. Dos meios à midiatização: um conceito em evolução. São Leopoldo: Unisinos, 2017.

LIPOVETSKY, Gilles. A terceira mulher: permanência e revolução do feminino. São Paulo: Companhia das Letras, 2000.

LIPOVETSKY, Gilles. 0 império do efêmero: a moda e seu destino nas sociedades modernas. São Paulo: Companhia das Letras, 1989.

LOPES, Maria Immacolata Vassallo de; BORELLI, Silvia Helena Simões; RESENDE, Vera da Rocha. Vivendo com a telenovela: mediações, recepção, teleficcionalidade. São Paulo: Summus, 2002.

MARTÍN-BARBERO, Jesús. Memoria y promessa: conversaciones con Jesús Martín-Barbero. Entrevistadores: Jorge Huergo e Kevin Morawicki. La Plata: EDULP, 2016.

MARTÍN-BARBERO, Jesús. A comunicação na educação. São Paulo: Contexto, 2014.

MARTÍN-BARBERO, Jesús. As formas mestiças da mídia. Entrevistadora: Mariluce Moura. Revista Pesquisa FAPESP, São Paulo, p. 10-15, 2009a. 
MARTÍN-BARBERO, Jesús. Uma aventura epistemológica. Entrevistadora: Maria Immacolata Vassalo de Lopes. MATRIZes, São Paulo, v. 2, n. 2, 2009 b.

MARTÍN-BARBERO, Jesús. Ofício de cartógrafo: Travessias latino-americanas da comunicação na cultura. São Paulo: Edições Loyola, 2004.

MARTÍN-BARBERO, Jesús. Dos meios às mediações: comunicação, cultura e hegemonia. Rio de Janeiro: Editora UFRJ, 2003.

MATA, Maria Cristina. De la cultura massiva a la cultura mediática. Diálogos de la comunicación, Lima, n. 56, p. 80-91, 1999.

NOVAES, Joana de Vilhena. 0 intolerável peso da feiúra: sobre mulheres e seus corpos. Rio de Janeiro: PUC-Rio, 2006.

RODRIGUES, Adriano. A gênese do campo dos media. In: SANTANA, R. N. Reflexões sobre o mundo contemporâneo. Rio de Janeiro: Revan, 2000. p. 201-221.

RONSINI, Veneza Mayora. A crença no mérito e a desigualdade: a recepção da telenovela do horário nobre. Porto Alegre: Sulina, 2012.

SCHMITZ, Daniela. Consumo, sentidos, usos e apropriações nas pesquisas de recepção: nem tão sinônimos, nem tão distantes. Intexto, Porto Alegre, n. 34, p. 255-275, 2015a.

SCHMITZ, Daniela. Moda e midiatização: aproximações e tensionamentos. In: COLÓQUIO DE MODA , 11., 2015, Curitiba. Anais... Curitiba, 2015b.

SCHMITZ, Daniela. O processo de midiatização e o sonho de ser modelo. Revista D'obras, São Paulo, v. 7, n. 15, p. 24-30, 2014a.

SCHMITZ, Daniela. A mediação da mídia no consumo midiático das modelos profissionais. In: CONGRESSO INTERNACIONAL EM COMUNICAÇÃO E CONSUMO, 4., 2014, São Paulo. Anais... São Paulo: ESPM, 2014b.

SCHMITZ, Daniela. Vivendo um projeto em família: consumo midiático, beleza feminina e o sonho juvenil de ser modelo profissional. 2013. Tese (Doutorado em Comunicação e Informação) - Programa de Pós-graduação em Comunicação e Informação, Universidade Federal do Rio Grande do Sul, Porto Alegre, 2013.

SIFUENTES, Lírian; ESCOSTEGUY, Ana Carolina. 0 mapa das mediações comunicativas da cultura: uma segunda onda na abordagem das mediações de Martín-Barbero? In: ENCONTRO ANUAL DA COMPÓS, 25., 2016, Goiânia. Anais... Goiás: Compós, 2016.

VERÓN, Eliseo. Esquema para el análisis de la mediatización. Diálogos de la comunicación, Lima, n. 48, p. 9-17, 1997.

WOLF, Naomi. 0 mito da beleza: como as imagens de beleza são usadas contra as mulheres. Rio de Janeiro: Rocco, 1992. 


\title{
The youthful desire to be a professional model and media mediation: an articulation since the contribution of Martín-Barbero
}

\begin{abstract}
This text brings part of the questioning from a thesis which investigated the relations between young girls' media consumption and the desire to follow a model career. The discussion proposed here is about the mediation of the media in this consumption process. The concept is operationalized since the contribution of Jesús Martín-Barbero, and the results point to media excellence as a mediation that helps to configure the character of "dream" that this desire obtains for the young girls interviewed.
\end{abstract}

\section{Keywords}

Mediations. Media consumption. Models. Fashion. Youth.

Recebido em 15/03/2018

Aceito em 12/05/2018 